Global Conferences Series:

Sciences and Technology (GCSST), Volume 5, 2020

Seminar Nasional I Baristand Industri Padang (Semnas I BIPD)

DOI:https://doi.org/10.32698/GCS-SNIIBI PD3439

\title{
Evaluation and stability test of immunomodulatory herbal syrups
}

\section{Evaluasi dan uji stabilitas sirup herbal imunomodulator}

\author{
Azlaini Yus Nasution ${ }^{1}$, Deri Islami ${ }^{1}$, Savita Salsabilla ${ }^{2}$, Wici Ersalinda ${ }^{1}$ \\ ${ }^{1}$ Prodi Farmasi, Fakultas Kedokteran dan Ilmu Kesehatan, Universitas Abdurrab, Pekanbaru, \\ Indonesia \\ ${ }^{2}$ Prodi Anafarma, Fakultas Kedokteran dan Ilmu Kesehatan, Univeritas Abdurrab, Pekanbaru, \\ Indonesia \\ E-mail: azlaini.yus@univrab.ac.id
}

\begin{abstract}
Herbal syrup is a type of food supplement used for children. Several types of herbal plant extracts can be formulated in this syrup preparation. The plant extract used is an immunomodulator to increase the child's immune system. In addition, plant extracts are added that are efficacious as an appetite enhancer, intelligence enhancer and for children's physical growth. To fulfill this property, a syrup preparation consisting of gotu kola extract, curcuma extract, albumin extract from snakehead fish, honey and date extract is made. The compounds that can modulate the immune system can be obtained from plants. Gotu kola extract can increase children's intelligence and curcuma extract can increase appetite. Albumin extract from fish such as snakehead fish can be used as a source of albumin to increase children's growth. Honey has antimicrobial activity and acts as an antioxidant. Date juice can be a source of energy and a source of iron and can treat constipation problems. This study aims to obtain data on the results of the evaluation and stability test of herbal syrup preparations. The results showed the characteristics of the syrup with a thick liquid texture, brown color and a distinctive smell. The pH of the resulting preparation is between 4.97-5.00 and the viscosity is between 0.516-1.440 poise. The $\mathrm{pH}$ of the herbal syrup has met the requirements of Indonesian Pharmacopoeia.
\end{abstract}

Keywords: herbal syrup; immunomodulators; food supplements; evaluation

\begin{abstract}
Abstrak: Sirup herbal adalah salah satu jenis food supplement yang digunakan untuk anak-anak. Beberapa jenis ekstrak tanaman herbal dapat diformulasikan dalam sediaan sirup ini. Ekstrak tanaman yang digunakan bersifat sebagai imunomodulator untuk meningkatkan daya tahan tubuh anak. Selain itu, ditambahkan ekstrak tanaman yang berkasiat sebagai penambah nafsu makan, penambah kecerdasan dan untuk pertumbuhan fisik anak. Untuk memenuhi khasiat ini dibuat sediaan sirup yang terdiri dari ekstrak pegagan, ekstrak temulawak, ekstrak albumin dari ikan gabus, madu dan sari kurma. Senyawa-senyawa yang dapat memodulasi sistem imun dapat diperoleh dari tanaman. Ekstrak pegagan dapat meningkatkan kecerdasan anak dan ekstrak temulawak dapat meningkatkan nafsu makan. Ekstrak albumin dari ikan seperti ikan gabus dapat dijadikan sebagai sumber albumin untuk meningkatkan pertumbuhan anak. Madu memiliki aktivitas antimikroba dan bersifat sebagai antioksidan. Sari kurma dapat sebagai sumber energi dan sumber zat besi serta dapat mengatasi masalah sembelit. Penelitian ini bertujuan untuk memperoleh data hasil evaluasi dan uji stabilitas sediaan sirup herbal. Hasil penelitian menunjukkan karakteristik sirup dengan tekstur berupa cairan kental, warna coklat dan berbau khas. $\mathrm{pH}$ sediaan yang dihasilkan antara 4,97-5,00 dan viskositas antara 0,516-1,440 poise. $\mathrm{pH}$ sirup herbal yang dihasilkan telah memenuhi syarat Farmakope Indonesia.
\end{abstract}

Kata Kunci: sirup herbal; imunomodulator; suplemen makanan; evaluasi

\section{PENDAHULUAN}

Saat ini, berkembang di pasaran beragam minuman kesehatan herbal sebagai food supplement yang komposisinya terdiri dari beberapa jenis herbal. Produsen menyebutkan khasiat dari produknya berhubungan

Copyright (C) 2020, the Authors. Published by Redwhite Press. 
dengan komponen penyusun minuman tersebut. Salah satu jenis food supplement yang tersedia adalah berbentuk sirup. Sediaan sirup ini banyak dibuat untuk konsumen anak-anak. Beberapa khasiat tanaman herbal yang diminati orang tua untuk anaknya antara lain: sebagai imunomodulator, penambah nafsu makan, penambah kecerdasan dan untuk pertumbuhan fisik anak. Khasiat dari berbagai macam tanaman herbal dapat diformulasi dalam satu sediaan yaitu dari ekstrak pegagan, ekstrak temulawak, ekstrak albumin dari ikan gabus, madu dan sari kurma.

Imunomodulator adalah substansi atau obat yang dapat memodulasi fungsi dan aktivitas sistem imun. Senyawa-senyawa yang dapat memodulasi sistem imun dapat diperoleh dari tanaman (Cidadapi, 2016). Ekstrak pegagan dapat meningkatkan kecerdasan anak dan ekstrak temulawak dapat meningkatkan nafsu makan (Lasmadiwati, 2003; Sina, 2013).

Ekstrak albumin dari ikan seperti ikan gabus telah dijadikan alternatif untuk mendapatkan albumin yang lebih murah dengan bentuk konsentrat dan food supplement (Listyanto and Andriyanto, 2009; Romadhoni et al., 2016). Madu memiliki aktivitas antimikroba sehingga dapat melawan peradangan dan infeksi, juga memiliki kemampuan untuk membersihkan luka, mengabsorbsi cairan edema di sekitar luka dan menambah nutrisi. Madu juga dapat mengobati luka bakar dan bersifat sebagai antioksidan (Hamad, 2007).

Sari kurma dapat sebagai sumber energi sebab gula alami glukosa, sukrosa, dan fruktosa tinggi di dalam kurma. Kadar zat besi yang tinggi pada kurma dapat mencegah anemia. Selain itu kurma dapat mencegah kanker usus besar dan dapat mengatasi masalah sembelit (Anton, 2010).

Pada proses pembuatan sirup ditambahkan bahan penstabil yang berfungsi sebagai bahan pembuat emulsi, pengental, pengisi, dan bahan pembuat gel. Gelatin sendiri berfungsi sebagai bahan penstabil pada sirup agar tampilan fisik sediaan dan homogenitas tercapai (GMIA, 2012). Formula sirup herbal yang dibuat pada penelitian ini adalah tanpa dan dengan penambahan gelatin sebagai penstabil sediaan. Tujuan penelitian ini adalah untuk memperoleh hasil evaluasi sediaan sirup herbal imunomodulator yang dibuat beserta uji stabilitasnya.

\section{METODE}

Penelitian ini merupakan penelitian true eksperimental laboratories yang meliputi formulasi, evaluasi dan uji stabilitas sediaan yang dihasilkan. Penelitian dilakukan di Laboratorium Makanan Fakultas Kedokteran dan Ilmu Kesehatan Universitas Abdurrab, pada bulan Februari sampai Agustus 2020.

Bahan yang digunakan pada penelitian ini adalah ekstrak pegagan, ekstrak ikan gabus, ekstrak temulawak, madu, kurma, gelatin sapi, natrium benzoat, perisa jeruk, aquadest, botol plastik. Alat yang digunakan adalah oven (Memmert), timbangan analitik (Kern), pH meter (Krisbow), viskosimeter, penangas air, blender (Miyako), mixer (Philips), pisau, dan alat-alat gelas. Tahapan penelitian terdiri dari persiapan bahan dan alat, pembuatan formulasi sirup, evaluasi sediaan, dan uji stabilitas sediaan sirup. Hasil evaluasi dan uji stabilitas sediaan sirup disajikan dalam bentuk tabel dan dibahas secara deskriptif.

\section{Pembuatan Formulasi Sirup}

Semua alat dan bahan disiapkan. Masing-masing bahan pembuat sirup ditimbang. Formula I dibuat dengan cara: ekstrak temulawak, ekstrak pegagan dan ekstrak ikan gabus dicampur dan ditambahkan sedikit aquadest. Lalu ditambahkan sari kurma dan madu, diaduk rata. Di wadah lain dilarutkan natrium benzoat, kemudian dimasukkan ke dalam campuran sebelumnya. Ditambahkan perisa jeruk dan sisa aquadest. Untuk formula II sama seperti formula I tetapi ada penambahan gelatin sapi. Formula sirup herbal yang dibuat tercantum pada Tabel 1.

Tabel 1. Formula sirup herbal.

\begin{tabular}{lll}
\hline Bahan & Konsentrasi (\%) & \\
\cline { 2 - 3 } & Formula 1 & Formula 2 \\
\hline Ekstrak pegagan & 1 & 1 \\
Ekstrak ikan gabus & 3 & 3 \\
Ekstrak temulawak & 3 & 3 \\
Madu & 20 & 20 \\
Sari kurma & 45 & 45 \\
Natrium benzoat & 0,02 & 0,02 \\
Gelatin sapi & - & 0,5 \\
Perisa jeruk & 0,1 & 0,1 \\
Aquadest sampai dengan & 100 & 100 \\
\hline
\end{tabular}




\section{Evaluasi}

Terdiri dari 1) Karakteristik sediaan. Sediaan sirup herbal diamati karakteristiknya meliputi tampilan fisik, warna dan bau. 2) Nilai pH. Pengukuran $\mathrm{pH}$ dilakukan dengan menggunakan $\mathrm{pH}$ meter. 3)Viskositas. Pengukuran viskositas dilakukan menggunakan viskosimeter.

\section{Uji Stabilitas}

Pengujian stabilitas pada sediaan sirup herbal dilakukan dengan menyimpan sediaan pada suhu kamar $\left(30^{\circ} \mathrm{C}\right)$ dan suhu $5^{\circ} \mathrm{C}$ masing-masing selama 12 jam sebanyak 10 siklus, kemudian dilakukan evaluasi meliputi: karakteristik sediaan, pengukuran $\mathrm{pH}$ dan viskositas.

\section{HASIL DAN PEMBAHASAN \\ Evaluasi Sediaan Sirup \\ Karakteristik Sediaan}

Hasil pengamatan karakteristik sediaan sirup herbal yang dibuat pada kedua formula dapat dilihat pada Tabel 2. Tampilan fisik sirup formula I berupa cairan agak kental dan pada formula F II sediaan lebih kental dibandingkan dengan F I. Hal ini disebabkan karena Formula I dibuat tanpa bahan penstabil, F II menggunakan bahan penstabil gelatin sapi. Gelatin berfungsi sebagai bahan pengental, pengisi, dan bahan pembuat gel (Boran and Regenstein, 2010). Warna yang dihasilkan pada kedua formula adalah sama, begitu juga dengan baunya memiliki bau khas yang sama. Bau khas yang dominan pada formula sirup ini adalah seperti bau jamu walaupun telah ditambahkan perisa jeruk. Bau khas jamu ini sebaiknya dikurangi agar bau sediaan lebih menarik. Sumber bau khas yang dominan berasal dari ekstrak pegagan dan albumin ikan gabus.

Tabel 2. Karakteristik sediaan sirup.

\begin{tabular}{lll}
\hline Karakteristik & F I & F II \\
\hline Tampilan fisik & cairan agak kental & cairan kental \\
Warna & coklat & Coklat \\
Bau & khas & Khas \\
\hline
\end{tabular}

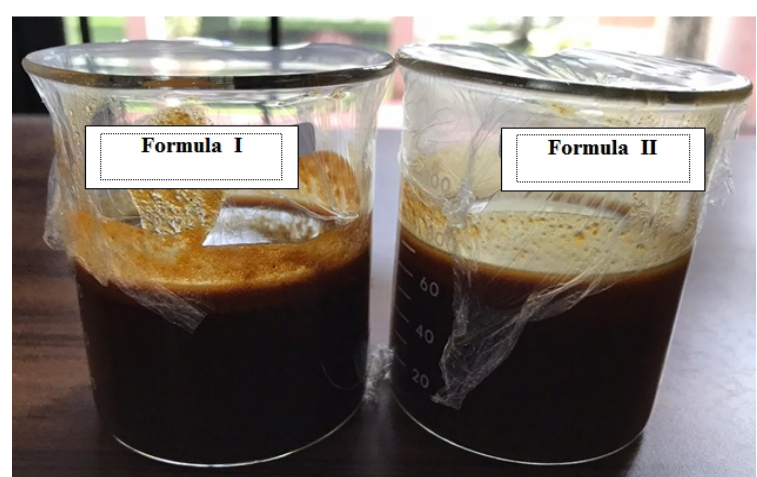

Gambar 1. Sirup herbal formula I dan formula II.

\section{Pengukuran pH dan Viskositas}

Parameter evaluasi pada sirup yang dilakukan berikutnya adalah pengukuran $\mathrm{pH}$ dan viskositas. Hasil pengukuran $\mathrm{pH}$ dan viskositas dapat dilihat pada Tabel 3. Nilai $\mathrm{pH}$ yang dianjurkan untuk sirup adalah berkisar antara 4-7 (Departemen Kesehatan RI, 2015). Hasil penelitian menunjukkan bahwa pH sediaan berkisar anatara 4,9-5,0, sehingga pada pengujian $\mathrm{pH}$ semua sirup yang dihasilkan memenuhi parameter nilai $\mathrm{pH}$ yang dipersyaratkan.

Viskositas adalah sifat ketahanan terhadap aliran suatu bahan yang berwujud cair, pasta, gel, dan bubur. Jika kekentalan yang rendah menjadikan cairan akan semakin mudah dituang dan sebaliknya, jika viskositas atau kekentalan semakin besar, maka cairan akan semakin sukar dituang (Dewi and Rusita, 2017). Viskositas sediaan sirup herbal ini antara 0,516 sampai 1,440 poise. 
Tabel 3. Hasil evaluasi sediaan sirup

\begin{tabular}{llll}
\hline \multirow{2}{*}{ Formula } & \multirow{2}{*}{ Ulangan } & Parameter & \\
\cline { 3 - 4 } & & $\mathrm{pH}$ & Viskositas (poises) \\
\hline \multirow{3}{*}{ F I } & 1 & 4,9 & 0,516 \\
& 2 & 5,0 & 0,703 \\
& 3 & 5,0 & 1,022 \\
& Rata-rata & 4,97 & 0,747 \\
\hline \multirow{2}{*}{ F II } & 1 & 5,0 & 1,221 \\
& 2 & 5,0 & 1,440 \\
& 3 & 5,0 & 1,437 \\
\hline
\end{tabular}

\section{Uji Stabilitas Sediaan Sirup}

Uji stabilitas sediaan sirup herbal ini menggunakan dua suhu yang berbeda yaitu suhu $5^{\circ} \mathrm{C}$ dan $30^{\circ} \mathrm{C}$. Sediaan sirup yang dibuat disimpan masing-masing pada suhu $5^{\circ} \mathrm{C}$ dan $30^{\circ} \mathrm{C}$, dan dilakukan evaluasi yang meliputi: karakteristik sediaan, pengukuran pH dan viskositas. Pada Tabel 4 dan 5 disajikan data evaluasi pengukuran $\mathrm{pH}$ dan viskositas hasil uji stabilitas.

Tabel 4. Hasil uji stabilitas pada suhu $30^{\circ} \mathrm{C}$

\begin{tabular}{|c|c|c|c|}
\hline \multirow[t]{2}{*}{ Siklus } & \multirow[t]{2}{*}{ Parameter } & \multicolumn{2}{|c|}{ Hasil Rata-rata } \\
\hline & & F I & F II \\
\hline \multirow{2}{*}{1} & $\mathrm{pH}$ & 4,97 & 5,00 \\
\hline & Viskositas (P) & 0,747 & 1,405 \\
\hline \multirow{2}{*}{2} & $\mathrm{pH}$ & 5,00 & 5,20 \\
\hline & Viskositas $(\mathrm{P})$ & 0,510 & 0,365 \\
\hline \multirow{2}{*}{3} & $\mathrm{pH}$ & 5,00 & 5,23 \\
\hline & Viskositas (P) & 0,590 & 0,348 \\
\hline \multirow{2}{*}{4} & $\mathrm{pH}$ & 5,07 & 5,27 \\
\hline & Viskositas (P) & 0,479 & 0,425 \\
\hline \multirow{2}{*}{5} & $\mathrm{pH}$ & 4,97 & 5,00 \\
\hline & Viskositas (P) & 0,424 & 1,197 \\
\hline \multirow{2}{*}{6} & $\mathrm{pH}$ & 4,93 & 5,03 \\
\hline & Viskositas (P) & 1,245 & 1,879 \\
\hline \multirow{2}{*}{7} & $\mathrm{pH}$ & 4,83 & 4,70 \\
\hline & Viskositas (P) & 0,279 & 0,411 \\
\hline \multirow{2}{*}{8} & $\mathrm{pH}$ & 4,80 & 4,73 \\
\hline & Viskositas (P) & 0,470 & 1,320 \\
\hline \multirow{2}{*}{9} & $\mathrm{pH}$ & 4,93 & 5,00 \\
\hline & Viskositas (P) & 1,478 & 2,473 \\
\hline \multirow{2}{*}{10} & $\mathrm{pH}$ & 5,00 & 4,97 \\
\hline & Viskositas (P) & 1,349 & 2,301 \\
\hline
\end{tabular}

Hasil pengukuran parameter $\mathrm{pH}$ pada uji stabilitas di setiap formula sirup baik penyimpanan pada $30^{\circ} \mathrm{C}$ maupun suhu $5^{\circ} \mathrm{C}$ masih memenuhi kriteria yaitu nilainya antara 4-7. pH rata-rata sirup herbal pada penyimpanan suhu $30^{\circ} \mathrm{C}$ untuk formula I berkisar antara 4,80-5,07, formula II 4,70-5,27. Penyimpanan pada suhu $5^{\circ} \mathrm{C}$ nilai $\mathrm{pH}$ formula I adalah 4,93-6,37 dan formula II yaitu 4,93-6,17.

Viskositas formula I penyimpanan suhu $30^{\circ} \mathrm{C}$ sebesar $0,279-1,478$ poise dan formula II $0,348-2,473$ poise. Uji stabilitas pada penyimpanan suhu $5^{\circ} \mathrm{C}$ diperoleh nilai viskositas $1,012-2,867$ poise pada formula I dan pada formula II antara 1,342-3,540 poise. Nilai viskositas dipengaruhi oleh suhu, pada uji stabilitas dengan penyimpanan suhu $5^{\circ} \mathrm{C}$ lebih tinggi dibandingkan dengan suhu $30^{\circ} \mathrm{C}$ hal ini karena viskositas suatu sediaan cair sangat dipengaruhi oleh suhu (Puspasari et al., 2009). 
Tabel 5. Hasil uji stabilitas pada suhu $5^{\circ} \mathrm{C}$

\begin{tabular}{llll}
\hline \multirow{2}{*}{ Siklus } & Parameter & Hasil Rata-rata & F II \\
\cline { 2 - 4 } 1 & & F I & 6,17 \\
& $\mathrm{pH}$ & 6,37 & 1,672 \\
2 & Viskositas (P) & 1,922 & 5,97 \\
& $\mathrm{pH}$ & 6,00 & 1,342 \\
3 & Viskositas (P) & 1,012 & 4,97 \\
& $\mathrm{pH}$ & 4,93 & 1,386 \\
4 & Viskositas (P) & 1,600 & 5,80 \\
& $\mathrm{pH}$ & 5,50 & 3,526 \\
5 & Viskositas (P) & 2,867 & 4,93 \\
& $\mathrm{pH}$ & 4,97 & 3,058 \\
6 & Viskositas (P) & 1,661 & 5,00 \\
\multirow{2}{*}{7} & $\mathrm{pH}$ & 4,97 & 3,245 \\
& Viskositas (P) & 1,971 & 5,00 \\
8 & $\mathrm{pH}$ & 4,97 & 3,455 \\
& Viskositas (P) & 2,222 & 5,00 \\
9 & $\mathrm{pH}$ & 4,97 & 3,540 \\
& Viskositas (P) & 2,032 & 4,97 \\
10 & $\mathrm{pH}$ & 4,97 & 3,245 \\
& Viskositas (P) & 1,954 & 4,97 \\
\hline
\end{tabular}

\section{SIMPULAN}

Sirup herbal pada formula II yaitu dengan penambahan penstabil gelatin sapi bersifat lebih kental dibandingkan dengan formula I. Hasil uji stabilitas menunjukkan bahwa sirup herbal yang dibuat bersifat stabil dengan nilai $\mathrm{pH}$ masih memenuhi syarat Farmakope Indonesia dan viskositas antara 0,279-3,540 poise.

\section{UCAPAN TERIMA KASIH}

Ucapan terima kasih disampaikan oleh peneliti kepada LPPM Universitas Abdurrab yang telah membiayai riset ini.

\section{REFERENSI}

Anton, R., 2010. Kurma. Samarinda: Universitas Mulawarman

Boran, G., Regenstein, J.M., 2010. Advances in food and nutrition research. 60th edn. Elsevier.

Cidadapi, A., 2016. Ramuan Herbal ala Thibun Nabawi: Mengupas pengobatan herbal di dalam thibun nabawi. Bandung: Putra Danayu.

Departemen Kesehatan RI, 2015. Farmakope Indonesia. 5th edn. Jakarta: Departemen Kesehatan RI.

Dewi, I.K., Rusita, Y.D., 2017. Uji stabilitas fisik dan hedonik sirup herbal kunyit asam. Jurnal Kebidanan dan Kesehatan Tradisional 2(2), 79-84.

GMIA, 2012. Gelatin Handbook. USA: Gelatin Manufacturers Institute of America.

Hamad, S., 2007. Terapi Madu. Jakarta: Pustaka Iman.

Lasmadiwati, E., 2004. Pegagan : Meningkatkan daya ingat, membuat awet muda, menurunkan gejala stress dan meningkatkan stamina. Jakarta: Penebar Swadaya.

Listyanto, N., Andriyanto, S., 2009. Ikan gabus (Channa striata) manfaat pengembangan dan alternatif teknik budidayanya. Media Akuakultur 4(1), 18-29.

Puspasari, D. P. W., Suter, I. K., Nocianitri, K. A., 2009. Pengaruh penutupan dan suhu pada proses perebusan terhadap karakteristik sirup wortel (Daucus carota L.). Agrotekno 15(1), 25-29.

Romadhoni, A.R., Afrianto, E., Intan, R., 2016. Extraction of snakehead fish (Ophiocephalus striatus) into fish protein concentrate as albumin source using various solvent. Jurnal Teknologi 78(4), 1-6.

Sina, Y. M., 2013. Sejuta Khasiat Herbal Temulawak. Yogyakarta: Diandra Pustaka. 